\title{
Gestation linked radical oxygen species fluxes and vitamins and trace mineral deficiencies in the ruminant
}

\author{
Bernard AurousseaU*, Dominique GRUFFAT, Denys DURAND \\ INRA Unité de Recherches sur les Herbivores, 63122 St-Genès-Champanelle, France
}

(Received 3 October 2005; accepted 18 September 2006)

\begin{abstract}
In mammals, radical oxygen species (ROS) are essential factors of cell replication, differentiation and growth (oxidative signal), notably during gestation, but are also potentially damaging agents. In Women, ROS play a role in remodeling of uterine tissues, implantation of the embryo, settlement of the villi and development of blood vessels characteristic of gestation. The body stores of vitamins and minerals of gestating females are used to keep ROS fluxes at a level corresponding to oxidative signals and to prevent an imbalance between their production and scavenging (oxidative stress), which would be detrimental to the mother and fetus. There is some evidence that, although based on different regulatory mechanisms, most of the effects of ROS reported in humans also occur in pregnant ruminant females, some of which have been actually reported. Many vitamins and trace elements have dual effects in the organism of mammals: (a) they are involved in the control of metabolic pathways or/and gene expression, (b) but most of the time they also display ROS trapping activity or their deficiencies induce high rates of ROS production. Deficiencies induce different disorders of gestation and can be induced by different kinds of stress. An example is given, corresponding to the decreased contents of cobalt of forages, when exposed to sustained heavy rains, so that the supply of vitamins B12 to the organism of the ruminant that grazes them is reduced and failure of gestation is induced. Outdoor exposure of ruminants to adverse climatic conditions by itself can increase the vitamin and trace element requirements. Adaptation of production systems taking into account these interactions between gestation and sources of stress or change of the quality of feeding stuffs as well as further developments of knowledge in that field is necessary to promote sustainable agricultural practices.
\end{abstract}

gestation / ovine / bovine / vitamins / trace elements / antioxidant enzymes / radical oxygen species / radical phenomena

\section{INTRODUCTION}

The present knowledge on the relationship between the physiological rate of ROS and healthy gestation as influenced by nutrition and the environment in ruminants is limited, so that farmers meet sometimes unexplained failure of reproduction.

\footnotetext{
* Corresponding author: aurou@clermont.inra.fr
}

The use of the more developed knowledge on physiological ROS production and the effects in pregnant women could help to understand and make the best of dispersed information on ROS production and effects in the course of gestation in ruminants. Different aspects are considered in this paper: ROS production, placental and fetal physiology, vitamin and micromineral element metabolism as well as the 
relationships between the environment and vitamin and mineral trace element intake, on the one hand, and outcome of gestation, on the other hand.

The thorough considerations of gestation in domestic animals that we develop address physiologic phenomena involved in oxidative signaling and risks of oxidative stress during gestation. Different sciences, i.e. physiology, veterinary and medical sciences, animal husbandry, agronomy and technology can participate in and benefit from new advances in this field. We already have given a functional review on these aspects [1].

\section{OVERVIEW OF RADICAL PHENOMENA}

Before handling our topic, it is necessary to help the reader with a general overview of ROS production and effects. A radical (reactive species) is formed when one atom of any molecule loses or gains one electron. Due to this unbalanced electronic configuration, radicals are extremely reactive with organic molecules. Two families of radicals, each including a large variety of species, can be distinguished: reactive oxygen species (ROS) and organic radicals. Organic radicals are large molecules that are very often integral parts of cell membranes. ROS originate in the organism from a large set of sources and their fate and their effects cover wide fields. Some very reactive radicals such as superoxide anion $\left(\mathrm{O}_{2}^{-\bullet}\right)$ or hydroxyl radical $\left({ }^{\bullet} \mathrm{OH}\right)$ readily reacts with cell components only at the site of their production, while others such as hydrogen peroxide $\left(\mathrm{H}_{2} \mathrm{O}_{2}\right)$ or nitric oxide $\left({ }^{\bullet} \mathrm{NO}\right)$ can diffuse across membranes to appreciable distances where new radicals are induced $[2,3]$.

ROS can induce cascade propagation of oxidative reactions between molecules, followed by formation of new radical species and, eventually, an exponential am- plification of rates of ROS production [48]. These chains of reactions are interrupted when the electronic disequilibrium of the radicals is corrected [9]. The correction of the disequilibrium is usually obtained by radical trapping by specialized components, specialized enzymes or non-specialized components or can also be obtained after condensation with another molecule to form a non reactive component $[7,10]$. These different events following initial ROS formation are commonly referred to as radical chains [2]. We preferentially use the term radical phenomena, which refers more readily to an enlarged set of poorly unraveled phenomena: (a) a competitive equilibrium between ROS production and elimination by vitamins, specialized enzymes, and a large variety of unspecialized components, (b) oxidative alteration of the tissues of variable importance and (c) interacting loops between hormones, cytokines, growth factors, ROS fluxes and protein expression and activity.

The attack and alteration of cell constituents by ROS is the more commonly reported effects of radical phenomena and is considered as "oxidative stress". Increasing rates of production of ROS relative to antioxidant defenses can induce increasing rates of oxidative alteration of lipids, proteins and DNA in the living organism, which can lead to pathologies or even achieve a non reversible state. For these deleterious aspects of ROS effects which are marginally related to our topic, we will direct readers to a small number of references only: two papers concerned with the alteration of proteins by $\operatorname{ROS}[6,10]$ and two references more concerned with pathological effects of radical phenomena and with their effects on lipid peroxidation $[2,7]$.

The alterations of cell components obtained are:

- Lipid peroxidation and breakdown of fatty acid molecules and formation of lipid derived carbonyles (notably 
malondialdehyde (MDA) and long chain fatty aldehydes), which are toxic when they reach high levels (notably through interaction with proteins) and fatty acid peroxides, which are non-radical components, but which, in interaction with free metal ions, can induce new radical chains. - Protein peroxidation, namely accompanied by:

(a) Inactivation of sulfhydriles and modification of protein conformation, inactivation of varied enzymes and ion channels, formation of varied organic radicals.

(b) Formation of protein peroxides, which are non radical components and, like their fatty counterparts, can induce new radical chains.

(c) Formation of protein carbonyls when radical chains are interrupted. Protein carbonyls are non radical components which are devoid of further initiation of radical chains on their own. However, cells with high contents of these components display impaired metabolism and growth. They bear testimony of the intensity of biological oxidations.

(d) Scission of proteins into smaller parts or liberation of free amino acids.

(e) Alteration of some amino acids, formation of lipoprotein adducts (among which lipofuschins, non-radical components, bearing testimony of the intensity of radical phenomena, but which, nevertheless, increases the response to stress thereafter).

- Oxidative inactivation and mutation of DNA.

- Destruction of vitamins and other components involved in protecting cell components, etc.

The large interest casted on oxidative stress must not silence the fact that, as long as there is an equilibrium between the production and the elimination of ROS, they have for the most part a positive effect on the organism. This is because radical formation is, in the first place, an essential component of cell metabolism, taking part in the catalysis of numerous enzymatic activities $[2,11]$ and in the fine control of cell metabolism through the control local redox potential $[11,12]$. ROS can be induced, as second messenger, by cytokines, oncogenes, growth factors or hormones [11,13-16]. ROS of external origin or resulting from some insult to the cells or from deviation of the usual metabolism of oxygen can mimic the effects of ROS induced as constitutive second messenger and can trigger activation of many transcription factors through the release of signaling proteins $[11,17,18]$. In this regard, T. Finkel [11] stated: "in many instances the production of reactive oxygen species is tightly regulated and their downstream targets exquisitely specific".

From the above statements, it is clear that, in the cells, there is a continuous production and disposal of ROS, some of which are fully linked to cell signaling and have been referred to as "oxidative signals" [11, 18].

As long as the equilibrium between rate of production of ROS of different types and antioxidant defenses is not disrupted, one can consider the result as oxidative signaling, because some adaptations of gene expression and cell metabolism follow the challenge by increasing rates of ROS production. However, in this situation, some cell components (lipids, proteins, DNA) are steadily altered: there is also a mild oxidative stress. But, over a large range of rates of ROS production, the attack of the organism is fairly efficiently counteracted and DNA and membranes are repaired before consistent damages are inflicted to the cells [19-21].

Extensive knowledge on radical phenomena specifically associated to healthy gestation and embryogenesis has been obtained or inferred in humans or in laboratory animals [8, 22-24]. As in other physiological states, ROS can induce noxious effects and pathologies of gestation only when the equilibrium between the 
production and the elimination of ROS is disrupted $[5,8,22,25]$. In the fetus exposed to an episode of ischemia, alteration of DNA can increase, in vivo, by a factor from 12 to 128 [25]. Despite active repair activities [19], some of the damaged DNA is subject to permanent alterations which can induce cellular apoptosis or tissue necrosis [26, 27], fetal growth retardation [27], death of the embryo [28] or latent pathologies $[29,30]$, some of which break out when the organism faces new disequilibria between ROS production and elimination, notably during postnatal life.

\section{ROS PRODUCTION IN GESTATING FEMALES}

\subsection{ROS production in the pregnant woman or gestating laboratory animal}

A large set of factors can induce high steady rates of $\operatorname{ROS}\left(\mathrm{H}_{2} \mathrm{O}_{2}, \mathrm{O}_{2}^{-\bullet}\right.$ and $\left.{ }^{\bullet} \mathrm{NO}\right)$ from the time of ovulation up to delivery: high rates of estrogens [14,31], cytokines, oncogenes and growth factor signaling [16], production by neutrophiles [8, 32] or activation of membrane NADPH oxidases by contact between tissues from the embryo and mother [33]. High levels of -NO are also observed in the circulation of pregnant women $[5,32]$ or gestating rats [27], notably produced by neutrophiles together with $\mathrm{O}_{2}^{-\bullet}$. ROS production by neutrophiles during gestation do not bear any relationship to their usual function, adherence, chemotaxis or phagocytosis [32]. The interaction of the two ROS is one of the sources of ${ }^{\bullet} \mathrm{OH}$ and of peroxynitrite $\left(\mathrm{ONOO}^{-}\right)$in the circulation of the gestating female $[5,27]$. In the rat, high rates of $\mathrm{O}_{2}^{-\bullet}$ (decreasing steadily from gestational day 12 to reach a $60 \%$ lesser level on day 16), of $\mathrm{H}_{2} \mathrm{O}_{2}$ (with an increase between days 12 and 14 and a $63 \%$ decrease between days 14 and 16 ) and of ${ }^{\circ} \mathrm{OH}$ (doubling between days 12 and 16) have also been recorded in ex vivo fetal homogenates [25].

\subsection{ROS production in the gestating ruminant}

The placenta in women or in murines are hemochorial while that observed in the ruminants is epitheliochorial, with some conjonctivochorial loci [34]. Despite these different types of placentation, several observations are in favor of some similarities between ROS phenomena in women and rats or in ruminants (cow, sheep). To figure what could happen at the beginning of gestation, we can consider the fact that, in the ewe or in the bovine, the blastocyst loses its zona pellucida respectively 7 or 10 days before implantation [34], whereas this phenomenon occurs at the moment of implantation in women. Therefore, an extended period of high rates of cell to cell contacts and triggering of NADPH oxidases and ROS fluxes is likely to occur in the ruminant. Moreover, ${ }^{\bullet} \mathrm{NO}$ radical production by peripheral bovine lymphocytes has been reported to be steadily increased by a factor of 3 between the non pregnantstate and the 7th day after conception and by a further factor of 1.5 between day 7 and days 90-120 of gestation [35]. A high expression of nitric oxide synthetase has also been reported in the endometrium and myometrium of the gestating ewe, up to the 140th day of gestation [36]. These observations infer that radical phenomena of physiological origin, although very likely subject to different mechanisms of control and different equilibria, are likely to display an equivalent intensity in the gestating ruminant as in monogastric species.

\section{ORIGIN AND INTEREST OF ROS PRODUCTION DURING GESTATION}

\subsection{Origin of ROS production during gestation}

The usefulness of ROS in gestating rats has been brought into evidence $[23,31]$. 
We have already listed several sources of ROS formation in the placenta and fetus in Section 3.1. More sources of ROS have been described, such as the triggering of radical phenomena by changes in oxygen partial pressures $[22,24,37,38]$ or synthesis of hormones [5]. ROS can also be formed after electron escape from the mitochondria of proliferating cells, favored by high rates of multiplication and metabolism and increased activity of mitochondrial superoxide dismutase (Mn-SOD) [39, 40] or, in human placental mitochondria, after interaction between NADPH and iron [41]. Other sources of ROS are increased activities of NADPH oxidases by contact between tissues from the embryo and mother or between replicating cells [33], interactions between estrogens and minerals [42] or triggering of NADPH peroxidases associated to the membranes inside the cells [43].

Rates of $\bullet \mathrm{OH}$ fluxes deserve consideration since they have been reported to increase in the 16 day old rat fetus, while $\mathrm{O}_{2}^{-\bullet}$ and $\mathrm{H}_{2} \mathrm{O}_{2}$ fluxes subside [25]. To explain these high ${ }^{\bullet} \mathrm{OH}$ concentrations in placental and fetal tissues observed in the rat and expected in the other species (actually reported in pathological states), $\mathrm{H}_{2} \mathrm{O}_{2}$ could diffuse across the membranes and react with redox minerals (mainly $\mathrm{Fe}$ ) in the cytoplasma [44], at the level of the nuclear membrane [43] or within the nucleus [45]. Direct formation of $\mathrm{O}_{2}^{-\bullet}$ production at the level of the nuclear membrane through an $\mathrm{NAD}(\mathrm{P}) \mathrm{H}$ dependent mechanism is possibly of major importance and can end in the interaction of this radical with iron to produce ${ }^{\bullet} \mathrm{OH}$ [43]. More means of ${ }^{\bullet} \mathrm{OH}$ formation can be recruited, such as interactions between $\mathrm{H}_{2} \mathrm{O}_{2}$ or $\mathrm{O}_{2}^{-\bullet}$ and iron [17] or interactions between various peroxides of proteins, lipids or catechols and redox minerals [2, 10, 42, 46]. In those instances, high rates of storage of iron occur in the placenta and in the fetus observed in various species including the bovine, starting from the early stages of pregnancy [47] and can be released through many different mechanisms [48]. The ${ }^{\bullet} \mathrm{OH}$ radical seems essential in several pathways of signal transduction, although it also induces risks of severe oxidative stress $[42,43,49]$.

\subsection{Oxygen partial pressure as a factor of ROS production during gestation}

Environmental oxygen partial pressure of living organisms is one of the basis of formation of ROS, notably at the level of placental tissue [22, 24, 37, 38]. It has been reported that oxygen partial pressure displays positive effects on embryo development only within a narrow range and that an oxidative stress can occur, with possibly potential lethal effects, below (slowing down of ATP synthesis) or above this range (direct peroxidation of membranes due to an excess of oxygen and radical chain initiation) [37]. In vitro, deviation of the oxygen partial pressures from the normal can induce oxidative stress and end embryo-toxicity if antioxidant enzymes (AOE) or antioxidant components are not provided [28, 50, 51]. During in utero embryo development, embryopathies occur, apparently due to oxygen induced ROS production, but in less well characterized circumstances $[28,50,52]$.

A good knowledge of variations of oxygen partial pressure in different parts of the reproductive tract and conceptus has been obtained in the monogastric, including the woman. Before implantation, the oxygen partial pressure in the lumen of the uterus settles between 20 and $37 \mathrm{~mm} \mathrm{Hg}$, regardless of the species of mammals considered [53, 54]. However, from in vitro studies, it appears that, inside the cells of the embryo, the oxygen partial pressure is 10 to 5 times lower than outside the cells, so that the induced rate of ROS production is lower than that expected from 
the external oxygen partial pressure [50]. At implantation, oxygen partial pressure at the level of the cytotrophoblasts is thus of the order of $14 \mathrm{~mm} \mathrm{Hg}$, which corresponds to a level of $2 \%$ of oxygen in the atmosphere, i.e. a condition of hypoxia which is likely to trigger cell multiplication and inhibit differentiation $[38,52]$. In the woman, invasion of spiral arteries by incompletely differentiated trophoblasts with slow motility occludes the tip of maternal vessels and limits maternal blood flow into the placenta $[22,38]$. Inefficient invasion of the spiral arteries can induce an unresolved placental oxidative stress and lead to pre-eclampsia $[5,8,22]$. Due to the occlusion of the maternal vessels by trophoblasts, the initial gradient of oxygen partial pressure between the mother (where it amounts to around $50-100 \mathrm{~mm}$ $\mathrm{Hg}$ ) and the embryo (where it amounts to around $14 \mathrm{~mm} \mathrm{Hg}$ ) is maintained after the 8th week of gestation and evolves slowly to $39.6 \mathrm{~mm} \mathrm{Hg}$ at a gestational age of 10 weeks $[38,52,54]$, the complete transformation of the spiral arteries being achieved only between weeks 18 and 20 of gestation [55]. In the conceptus, the low initial oxygen partial pressure evolves only slowly between the 10th and 16th week of pregnancy from 64.3 to $73.2 \mathrm{~mm} \mathrm{Hg}$ at the level of decidua, from 25.6 to $56.2 \mathrm{~mm} \mathrm{Hg}$ at the level of the placenta, and, remains unchanged during this interval at the level of the coelomic fluid, i.e. between 20.0 and $18.2 \mathrm{~mm} \mathrm{Hg}$ [54]. The initial preservation of relatively low oxygen partial pressure at the level of the placenta and fetus in the human caused by the occlusion of the maternal vessels is matched in the ruminant by the occurrence of several membranes between the blood of the dam and of the fetus, which also preserve a relatively low oxygen partial pressure at the level of the placenta and fetus, so that the patterns of ROS induced by oxygen in the fetuses of the two species are likely to share similar intensities.

\subsection{ROS formation in the mitochondria of placental and fetal tissues}

At the different stages of pregnancy a high energy metabolic rate is observed [56], but is automatically followed by a high flux of ROS, originating notably from the mitochondria $[25,39,40]$. Several features specific to embryogenesis increase mitochondrial production of $\mathrm{O}_{2}^{-\bullet}$ and $\mathrm{H}_{2} \mathrm{O}_{2}$, since, as opposed to the situation in the adult, an initial imbalance between enzymatic production of electrons (NAD dehydrogenase and succinate deshydrogenase), on the one hand, and the ability of the respiratory chain to use them for ATP synthesis (cytochrome oxidase), on the other hand, are seen in the fetus [37].

More mechanisms are involved in the control of ROS production at the level of the mitochondria (Fig. 1) and are of major importance for the positive outcome of gestation. In this respect, vitamin B1 plays a major role and its deficiency is lethal during the early part of gestation [57]. This vitamin affords some protection to the early embryo both because it prevents an extensive use of electrons for ROS production after releasing the feedback of ATP on its synthesis [58] and because it traps ROS efficiently [59].

In women, vitamin A deficiency during specific states of pregnancy is lethal and a deficiency in the control of the development of different organs linked to a lack of expression of some genes has been described [29]. However, vitamin A deficiency is also followed, in rats, by an increase of malondialdehyde (a marker of peroxidation of lipids) and of 8-oxo7, 8-dihydro-2'-deoxyguanosine (a marker of the peroxidation of DNA) and by decreases of the mitochondrial GSH content and GSH/GSSG ratio [60]. Vitamin A can detoxify organic peroxides in vitro [61], but is extensively catabolized in the process. This suggests that ROS trapping could be the origin of the momentary 


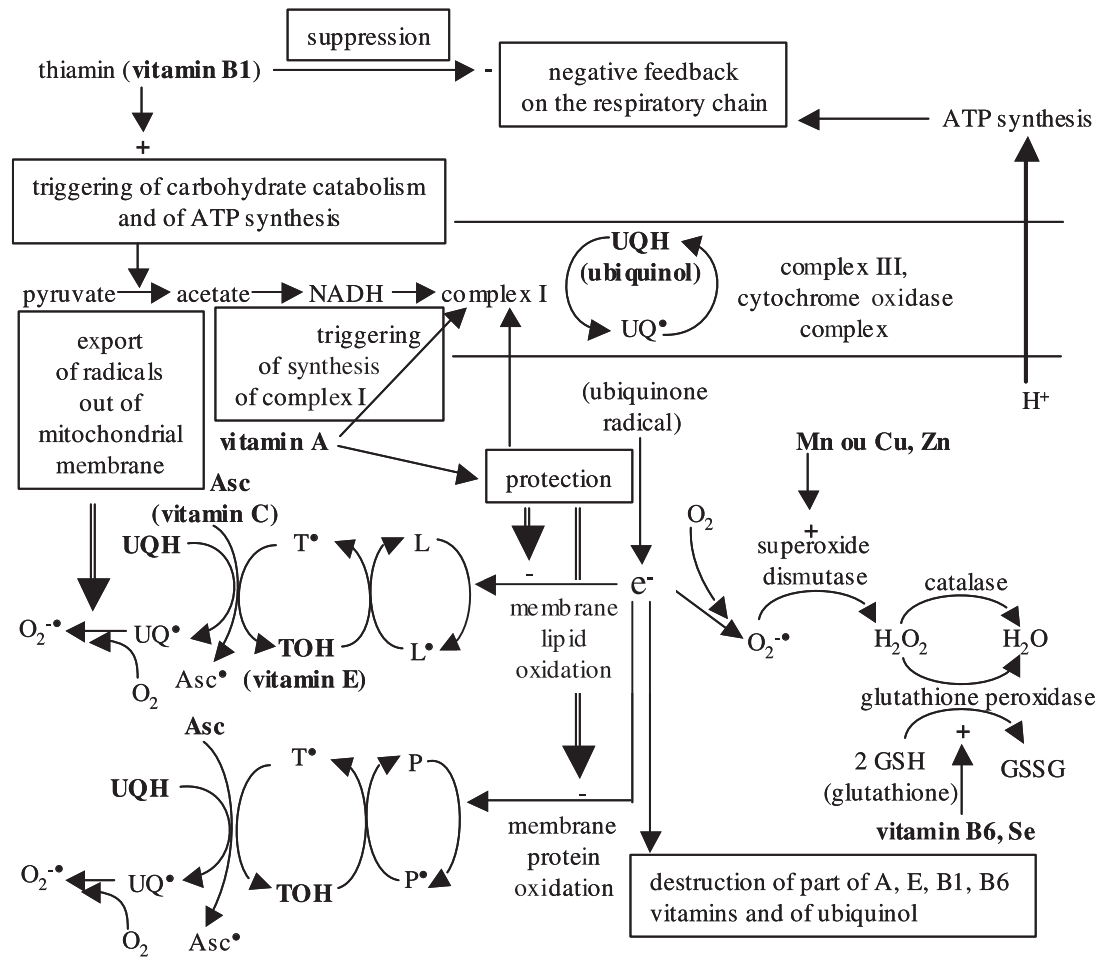

Figure 1. Control of radical phenomena originating from mitochondria $\left(\mathrm{L}=\right.$ lipids, $\mathrm{L}^{\bullet}=$ lipid radical, $\mathrm{P}^{\bullet}=$ protein radical, $\mathrm{UQ}^{\bullet}=$ ubiquinone radical, $\mathrm{T}^{\bullet}=$ tocopheryl radical, Asc $\boldsymbol{\bullet}^{\bullet}=$ ascorbyl radical).

decrease of vitamin A stores in the rat fetus between days 10-14, at the time of induction of organ differentiation [62] and of the synergic effect with vitamin $\mathrm{E}$ in ROS trapping [21]. Vitamin A also negatively regulates the TNF- $\alpha$ pathway and affords protection of the placenta against ROS by that mean [63].

In vitro, supplements of vitamin $\mathrm{E}$ have also been reported to protect the integrity of the human placental mitochondria through a dose dependent inhibition of lipid peroxidation [41]. In this study, a synergy was observed between the antioxydant potential of vitamins $\mathrm{E}$ and $\mathrm{C}$, independently of the $\mathrm{Fe}^{3+} / \mathrm{Fe}^{2+}$ ratio, and was thought to be related to recycling of vitamin $E$ by vitamin $C$. In vivo sparing of vitamin $\mathrm{E}$ by vitamin $\mathrm{C}$, GSH, lipoic acid or ubiquinols has been confirmed in laboratory animals, involving or not enzymatic activities for the recycling of the tocopheroxy radical [64].

In the mouse, a mutation replacing ubiquinone, UQ, the cofactor of the mitochondrial respiratory chain, by demethoxyubiquinone has been shown to reduce by $35 \%$ the mitochondrial oxygen consumption and to induce an arrest of the development of the embryo [65]. Moreover, in cell cultures, targeting a ubiquinone derivative to the mitochondria inhibited lipid peroxidation of the organelle's membrane as well as apoptosis [66], while endogenous ubiquinol also protects both lipids and proteins of beef heart 
sub-mitochondrial particles against oxidation [46].

In rat embryo culture, embryopathy can be induced by a high concentration of oxygen $(20 \%)$ which can increase the rate of $\mathrm{H}_{2} \mathrm{O}_{2}$ formation (+180\%) and decrease the GSH content in the cells [28]. Two enzymes associated with ROS trapping by $\mathrm{GSH}$, glutathione peroxydase (Gpx) and glutathione reductase (Gred), which could help to maintain the GSH content of the cells, are respectively dependent on vitamin B6 [67] and B2 [68]. The two vitamins undergo extensive oxidative degradation after ROS trapping $[69,70]$ and the depletion of the mitochondrial content of the 2 vitamins, can aggravate the detrimental effect of high rates of ROS production. Another enzyme of GSH metabolism, phospholipid hydroperoxide glutathione peroxidase (PHGpx or Gpx-4) is essential to avoid the death of the embryo [71]. Mitochondrial PHGpx is essential to inhibit the peroxidation of mitochondrial phospholipids and the release of apoptotic factors from the mitochondria [72]. PHGpx has been shown to display a synergic effect with vitamin $E$ on the protection of PUFA: it eliminates the lipid hydroperoxides formed from the reaction of lipid hydroperoxyl radicals with the vitamin before any reinitiation of peroxidation [73]. Two other AOE, namely Mn-SOD [74] and catalase (CAT) [40] are also important to prevent detrimental increases of rates of ROS production in the fetal mitochondria.

\section{INTEREST OF ROS PHENOMENA IN THE GESTATING MAMMAL}

\subsection{Interest of ROS phenomena in the gestating mammal: implantation}

As reported in the previous section, the exposure of the blastocyst or the embryo to oxygen induces risks of oxidative stress and of gestation failure or pathologies.
However, our topic is centered on normal gestation where high physiological rates of ROS production have been reported in the uterine wall (Section 3). In the rabbit, after a contact is established between the cells of the blastocyst and of the uterus, an extensive membrane lipid peroxidation occurs as a result of ROS exposition, and phospholipase A2 is triggered, notably by lipoperoxides, and leads to an intensive degradation of membrane phospholipids [75]. In the human, high rates of thiobarbituric acid reactive substances (TBARS) have also been reported and bare testimony of high rates of lipid peroxidation during the first term of healthy gestation, both at the level of the placenta or in the fetal liver [76]. The precise time scale of events is not known, but the high physiological rates of ROS production and related responses (notably lipid peroxidation) are very likely to induce uterus oedema and to increase degradation of the extracellular matrix, fluidity of the membranes and fusion between cells from the outer blastocyst layer (at the syndesmochorial loci) or between the cells from the surface of the endometrium and of the fetus $[23,52]$. They are also thought to facilitate the formation of the decidua, the remodeling of placental tissues and the development of specific blood vessels, as well as trophoblast invasion $[38,52]$. The effects of the vascular endothelium growth factor (VEGF) on permeability and angiogenesis were established a long time ago: after further investigation, it appears that VEGF induces ROS formation as a second messenger to induce a cascade of reactions leading to the final reported effect [11]. ROS also increase membrane permeability, which can allow ameliorated import of nutrients (at least into the placenta, through non specific increase of permeability) as well as export of altered components from the cells $[8,52]$.

An apparented type of event has been described in the bovine, with trophoblast giant cells, migration into the endometrium 
and fusion with uterine epithelial cells [77]. Keeping in mind that the peculiarities of each species do not preclude a large common set of metabolic events leading to ROS production in ruminant animals, women or rodents, the numerous results obtained in the monogastric species give us some general clues on the ROS flux origins and effects.

\subsection{Interest of ROS phenomena in the gestating mammal: hyperplasia}

The regulation of cellular hyperplasia by ROS has been described in vitro on cultured cells $[26,40]$. Cellular proliferation is slow when ROS levels are low and increases with increasing levels of ROS until achievement of a threshold, after which proliferation is blocked and replaced by differentiation, apoptosis or necrosis. In these studies, removal of ROS from the incubation medium is also able to decrease their positive (moderate ROS levels) or adverse effects (high ROS levels) on cellular proliferation.

\subsection{Interest of ROS phenomena in the gestating mammal: differentiation}

Different examples of the induction of differentiation by hormones, cytokines, oncogenes or growth factors have been obtained, but further studies underline the absolute requirement of ROS signaling to obtain these effects $[40,78]$. The precise circumstances and mechanisms and the cascade of regulatory factors involved in the differentiation of the embryo have not been fully elucidated and involve paradoxical issues, but a change in the redox potential in the cytoplasm, obtained mainly through increased oxidation of GSH, is usually observed at the time of gene induction $[12,79]$. A so-called oxidative burst drastically increasing ROS fluxes has been repeatedly observed at the time of the swing from hyperplasia to differentiation $[11,22,80]$, notably in the embryo, being triggered by a brisk increase of oxygen partial pressure allowed by the disconnection of the trophoblastic plugs [22].

\subsection{Gene signaling and cell motility at the time of implantation}

Up to the time of blastocyst implantation, the low oxygen partial pressure found at the level of the cytotrophoblasts corresponds to a level of $2 \%$ of oxygen. Under this low oxygen partial pressure, hypoxia triggers transcription and stabilization of hypoxia inducible factor-1, HIF-1 [81], apparently as a result of a low rate of $\mathrm{H}_{2} \mathrm{O}_{2}$ released at the level of complex III of the respiratory chain [82]. HIF-1 is involved in placentation and slow migration of the cytotrophoblasts into the spiral arterioles, where they are progressively exposed to higher oxygen partial pressure $[22,38,54]$. Above a level of $40 \mathrm{~mm} \mathrm{Hg}$ (6\% oxygen), $\mathrm{O}_{2}^{-\bullet}$ and ${ }^{\bullet} \mathrm{OH}$ radicals are formed, HIF1 is submitted to proteolysis [22, 38, 81] and the change in the equilibrium between the different oncogenes in invasive cytotrophoblasts induces them to fully differentiate, to acquire more motility, to invade the maternal blood vessels more deeply [38], to release the occlusion of the maternal arteries and to convert the maternal arteries into distended utero-placental ones which allow an increase of the blood flow to the conceptus $[22,38]$.

The functionality of the interrelations between other genes, such as AP-1, and ROS on the development of the placenta and their changes with other metabolic features are not fully solved and will not be dealt with here. As in the human, proteins of the cfos/jun family are expressed in the ovine trophoblasts and, prior to the implantation of the embryo: they are expressed, together with the ruminant 
specific interferon- $\tau$ [83], at a time when extensive growth and remodeling of the blastocyst occur [84]. Along with the scarce data on ROS fluxes, the effects of cell to cell contact or cell fusion already discussed, this additional observation plays in favor of a large common set of features of gestation in ruminants and monogastrics.

\subsection{Mn- and $\mathrm{Cu} / \mathrm{Zn}-\mathrm{SOD}$ induction and control}

We will focus on a complete chain of events involved in some aspects of the regulation of differentiation and growth (Fig. 2) and which makes obvious the involvement of physiological, non detrimental, high ROS fluxes in these changes. A cascade of events thus starts from ROS production in the mitochondria, includes the TNF - NF- $\kappa \mathrm{B}$ pathways and ends in the induction of $\mathrm{Mn}-$ and $\mathrm{Cu} / \mathrm{Zn}-\mathrm{SOD}$, which confers adaptation of the cells and of the organism to sustained episodes of oxidative stress [12,39,85].

In the monogastric, after establishment of a fetal blood vessel network, gradients of oxygen partial pressure within the physiological range of $5-30 \mathrm{~mm} \mathrm{Hg}$, become steeper and more complex within the fetus [80]. Gradients of hormones and nutrients, notably retinoic acid [86], are also observed, but are out of the scope of our paper and have not been considered in this review.

Different factors of regulation are involved in the expression of $\mathrm{Cu} / \mathrm{Zn}$ - and $\mathrm{Mn}-\mathrm{SOD}$, but the regulation of the expression of the 2 enzymes can be differentially modulated by ROS fluxes: sustained fluxes of ROS per se induce transcription of $\mathrm{Cu} / \mathrm{Zn}$-SOD, while a short exposure to ROS also induces, per se, transcription of Mn-SOD [87].

It is always difficult to sort out the early events and their chronology or to sort out the controlling factor from the accompanying ones. However, at the time of appearance of the 2 antioxidative enzymes, relatively high rates of fluxes of $\mathrm{O}_{2}^{-\bullet}, \mathrm{H}_{2} \mathrm{O}_{2}$ and $\bullet \cdot \mathrm{OH}$, seemingly formed inside the cells, at the level of all subcellular organelles, have been reported in 12 to 16 day old rat embryos and display different timely patterns of changes [25]. $\mathrm{Cu} / \mathrm{Zn}$-SOD does appear earlier than MnSOD in the rat fetus [88], at a time when $\mathrm{O}_{2}^{-\bullet}$ fluxes are at their maximum [25]. MnSOD and mitochondria, where Mn-SOD is strictly located, follow parallel initial appearance, inhibition or loss $[89,90]$. Due to the development of $\mathrm{Cu} / \mathrm{Zn}-\mathrm{SOD}$, the very active and deleterious $\mathrm{O}_{2}^{-\bullet}$ radical is dismutated into $\mathrm{H}_{2} \mathrm{O}_{2}(40 \%$ decrease and $40 \%$ increase of their respective rates of production [25]). $\mathrm{H}_{2} \mathrm{O}_{2}$ can then diffuse to the site of its action and is more readily a signaling molecule $[7,78]$. The decrease of $\mathrm{O}_{2}^{-\bullet}$ concentrations in the cells can change the effects of this radical from an initial deleterious effect $[89,90]$ into an oxidative signal [78]. Mitochondria remain functional and allow cell growth only when it is equipped with sufficient Mn-SOD to dismutate mitochondrial $\mathrm{O}_{2}^{-\bullet}$ into $\mathrm{H}_{2} \mathrm{O}_{2}$ [39].

Thereafter, Mn-SOD expression and activity in differentiated cells appear to be controlled by a loop of events related to the equipment of the cells with mitochondria and Mn-SOD. As reported in Section 4.1 several means can explain the increase of - OH fluxes reported in the rat fetus towards the 16th day of gestation [25]. After being formed, the ${ }^{\bullet} \mathrm{OH}$ radical seems to alter the redox status of GSH or sulfur-proteins at the site of its formation as a major mean of control of gene expression [12]. The hypothesis of a prominent role of $\mathrm{H}_{2} \mathrm{O}_{2}$ diffusion out of the mitochondria or into the nucleus is suggested by the loss of effect of $\mathrm{H}_{2} \mathrm{O}_{2}$ on gene expression after strong chelation of the redox minerals within the cells or by the absence of effect of ${ }^{\bullet} \mathrm{OH}$ when $\mathrm{H}_{2} \mathrm{O}_{2}$ is reacted with free $\mathrm{Fe}$ added 


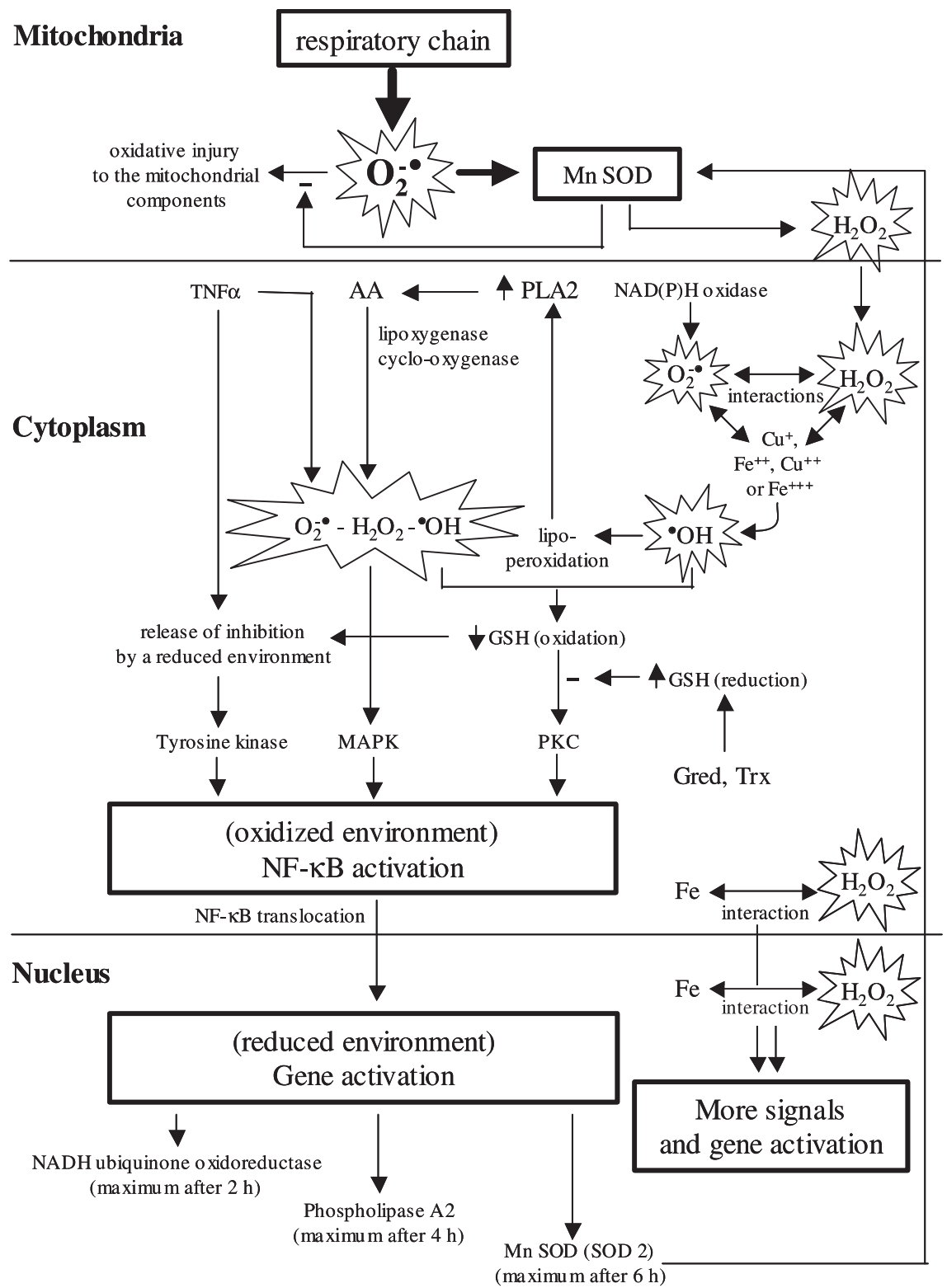

Figure 2. Selected aspects of the involvement of radical phenomena in the differentiating embryo. $\left(\mathrm{O}_{2}^{-}\right.$: superoxide radical, $\mathrm{H}_{2} \mathrm{O}_{2}$ : hydrogen peroxide, ${ }^{\bullet} \mathrm{OH}$ : hydroxyl radical, Mn-SOD: Mn superoxide dismutase, PLA2: phospholipase A2, AA: arachidonic acid, Gred: glutathione reductase, Trx: thioredoxin reductase). 
to a cell homogenate $[44,45]$. Suppression of ROS fluxes can suppress the expression of both $\mathrm{Mn}$ - and $\mathrm{Cu} / \mathrm{Zn}-\mathrm{SOD}$ [78]. Moreover, the coordination of the whole set of regulatory events and its relation to oxygen partial pressure can be altered by variation of the cellular contents of the ${ }^{\bullet} \mathrm{NO}$ radical, because this compound inhibits HIF- $1 \alpha$ stabilization under hypoxia [52] or its oxidation under normal oxygenation [91], or, again, triggers GSH synthesis to change the redox environment and the control of gene expression [15].

A large set of factors can be recruited by different means and are involved in the regulation of the expression of both enzymes and other proteins: TNF $\alpha, \mathrm{NF}-\kappa \mathrm{B}$, cytokines, protein kinases, AP-1 [12, 78, $85,87,92]$. The mechanistic aspects of the regulation of gene expression by those factors are well known, but not the precise functionality aspects of these convergent or alternative pathways of control, with regards to the relation with ROS fluxes and to the time pattern of embryo differentiation and development.

\subsection{Defense against ROS and the outcome of gestation}

The placenta and fetus must be protected to avoid any lethal effect of the high rates of ROS production as already mentioned in Section 4.3. A limited survey of the literature points to evidence of dual roles of several components, mineral trace elements or vitamins, both as factor of control of the metabolism and as radical trapping agents.

GSH production and metabolism are of the utmost importance to prevent pathologies of gestation $[5,8,28]$, both for the radical scavenging properties of GSH $[12,28]$ and for its role in the control of the redox status inside the cells and the control of gene expression [12,79]. Another radical trapping component, ubiquinone, which is also essential for energy metabolism [65] has also been reported to be essential for gestation outcome or viability of stem cells in the mouse.

Protection of cell structures is also afforded by a set of enzymes specialized in defense against ROS: $\mathrm{Mn}-\mathrm{SOD}, \mathrm{Cu} / \mathrm{Zn}$ SOD, CAT, Gpx, Gred and PHGpx have already been listed. An extracellular SOD (EC-SOD) [93], a ubiquitous thioredoxin $[12,20]$ and peroxiredoxin, an enzyme controlling ROS concentration at the level of the nuclear membrane [49], are also important in the same respect. The seven enzymes, the activities of which are dependent on mineral trace elements, are essential for the positive outcome of the reproduction both in monogastrics and in ruminants [29, 49, 50, 71, 94-96].

Different vitamin deficiencies have also been reported to impair the outcome of pregnancies or gestation, some of which seem clearly related to the detrimental ROS effect: vitamin $\mathrm{E}$ in women [29] or vitamin C in the sow [97]. In pre-eclamsia prone women, significant prevention of the pathology is obtained after supplementation with a mixture of vitamin $\mathrm{E}$ and $\mathrm{C}$ between the 16th and 22nd weeks of pregnancy [98]. Other studies do not include any explanation for gestation failure with vitamin A in women [29], vitamin B1 in the rat [57], vitamin B2 in women [99], vitamin B9 in women [100] or in the pig [101] or vitamin B12 in the ewe $[88,102]$. Vitamin B2, which seems essential for the health of the fetus or adult [103], displays paradoxical ROS trapping activity [69] or, when added into cell culture medium, prooxidative activity [104]. These findings underline that we need to learn more on the mechanisms of vitamin action and dual potential. Conflicting observations are obtained on the role of vitamin B1 deficiency in gestation failure: secretion of pituitary hormones or estrogen do not seem to be impaired despite a loss of appetite in gestating rats [57], while this vitamin can be 
recruited and activated in cells of the pituitary or blood vessel walls scavenging damaged cell components after an episode of ischemia [105] and is also an efficient ROS trapping component [59]. Increased rates of ROS fluxes have been reported in vitamin A, B2, B6, B9 or B12 deficiencies $[60,94,106-108]$ which, together with the ROS trapping ability of these compounds $[21,60,61,69,70,109,110]$, points to some relationship to ROS phenomena, in addition to their effect on the control of gene expression and metabolism $[29,65,67,68$, 110-112].

Satisfaction of the requirements of the gestating female must be worked out in relation to long term effects of transitory deficiencies. This statement is based on a study where an episode of vitamin B12 deficiency in young ewe lambs displayed long term effects, only corrected by a long period of supplementation [76]. Ewes raised on marginally Co deficient pastures and receiving Co supplements continuously during two consecutive year seasons (calculated to meet gestation requirements), compared to ewes raised in the same environment and receiving the same level of Co supplements 5 months before the second breeding season and throughout gestation, displayed a higher numerical productivity (116 against 83 lambs for 100 ewes), and their lambs displayed significantly higher live-weight gains between 8 and 14 weeks of age (+38\%) [76]. In this experiment, the marginally Co deficiency during grazing was induced by heavy rains observed during gestation, with a drop of about $40 \%$ of the Co content of grass, as previously reported by others [113]. Another study brought into evidence year to year variations of cobalt status in ewe lambs reared outdoors, with significant decreases of circulating levels $(-33 \%)$ or hepatic stores $(-25 \%)$ of vitamin B12 during periods of the years where increased rainfall occur and significant decrease of growth under a threshold level [114]. Thus exogenous circumstances such as periods of heavy rain can decrease the satisfaction of the vitamin B12 requirements of the gestating females after decreasing the Co content of the grazed forage. The Co content of the conserved forage grown and harvested after periods of heavy rains can also be decreased under such circumstances. In addition, direct loss of vitamins and mineral trace elements from the organism of the animals can occur during exposure to an external stress (such as for example, a climatic stress), since MS-Co(II), an inactivated form of vitamin B12 produced by oxidation of MS-Co(I) in the course of enzymatic methionine synthesis, can be oxidized by ROS [110, 115]. Indeed, inactivation of vitamin B12 by ${ }^{\bullet} \mathrm{NO}$ [115] has been reported and is involved in pernicious anemia in humans, after disturbing both methionine synthesis and carbon flow through the folate pathway [116].

A second level of the effects of vitamin deficiencies encountered in the course of pregnancy or gestation concerns the adverse effects on the health of the mother $[96,117]$ and on the development and viability of the new-born. Thus, the growth and resistance of the newborn can thus be lowered after a period of deficiency in one or several vitamins or trace mineral elements, i.e. vitamin B12 [102,118], vitamin E [119], copper [120] in ovines or after a period of deficiency of selenium $(\mathrm{Se})$ in bovines [121] or in ovines [122]. Some of these consequences are linked to the fact that newborn animals usually face a period of high demand immediately after birth, caused notably by a brisk change of the oxygen partial pressure at the level of lungs and other sources of ROS production. In this respect, a lack of folic acid could be involved in the poor vitality of some newborn lambs or calves, despite the fact that no folic acid deficiency has been reported in gestating ruminants. Folic acid requirements are usually thought to be easily met by synthesis in the rumen, where 
it requires less Co than vitamin B12 to achieve a maximum rate of synthesis [123]. However, the rate of synthesis of folic acid could be reduced to a large extent when the ingested grass has lost a large part of its Co content under heavy rain, and, since this vitamin is a ROS trapping component [109], it could be further destroyed by ROS in ruminants exposed to stress. In young heifers, circulating folic acid level is relatively low and this vitamin is apparently more quickly disposed of than in older animals [124,125], while supplements of this vitamin can significantly increase the rate of growth of young ruminants, suggesting that the requirements are very often not met at the time of birth [126]. Folic acid supplementation of gestating cows increases folic acid levels in the blood of newborn animals by $24 \%$ and folic acid levels in colostrum by 54\% [127] and could be of relevance in preventing postnatal pathologies of their progeny. Similarly, the 3 week delay necessary between Se supplementation and the expected increase in Gpx activity does not allow the newborn deficient in Se to face ROS exposure, while an increase of the supply in utero (supplementation of the ewe before mating) provides the newborn lamb with the desired Gpx activity at birth [122]. Similarly, Gpx is increased or not at calving whether the cows receive supplemental Se during the last 7 weeks or 4 weeks of gestation [121]. This latency of the effects of supplementation could also be of relevance to earlier periods of gestation, when the protection of the maternal and fetal organisms are required and extensive oxidative destruction of the different AO components (including vitamins) or enzymes could deplete the cell contents below the threshold value necessary for their role in the control of specific gene induction.

Several situations have been reported where the pathologies induced by vitamin or mineral trace element deficiencies during fetal life or growth could not read- ily be cured later. These long lasting effects have received little attention because they are very likely due to the interactions between several deficiencies. Thus, $\mathrm{Cu}$ deficiency during pregnancy has been shown to induce postnatal malfunctions [96]. In rodents, sub-optimal $\mathrm{Zn}$ or $\mathrm{Cu}$ nutrition during gestation also induces postnatal malfunctions as well as long lasting immunological and biochemical impairments in the adult [30]. Since part of the mechanisms of induction of the effects of deficiencies are very likely similar in the embryo or during postnatal life, an illustration of the interaction between several factors was obtained in young growing lambs [128]. In this study prevention of abnormality of bone marrow or other health defects were observed only in a group of lambs continuously fed a diet sufficient both in vitamins E and B12. After a 9 month period of either vitamin $\mathrm{E}$ or vitamin B12 deficiency, a period of 13 to 17 months on a sufficient diet failed to correct the induced health troubles. More evidence of such long lasting effects, have also been seen in the young child: the remanent effects of a vitamin B12 deficient diet between birth and 6 years of age were still obvious after an equilibrated regimen between the ages of 6 and 12 years [129].

\section{CONCLUSIONS}

The increasing interest for radical phenomena during the last 20 years has taught us that the supply of oxygen to the organisms of mammals, essential for energy metabolism, also raises some risks of damaging peroxidative insults and induced pathologies. During gestation and embryogenesis, the organism of the mother and embryo are the site of physiological high rates of ROS production, primarily involved in cell signaling and control of the development of the fetus: replication, 
differentiation and maturation of the fetal cells and organs.

However, exaggerated rates of production of ROS can be involved in paradoxical effects and can lead to breakdown of vitamins and mineral trace-elements associated to enzymes specialized in the defense against ROS and can end in peroxidation of cell components and induction of pathologies and gestation failure.

Such episodes of exagerated rates of production of ROS are induced after exposition of breeding females to different stresses, and seem to be more easily prevented by equilibrated provision of different vitamins or mineral trace elements than by single supplementation. Among the different types of stress, climatic stress has been reported to display major adverse effects on health and reproduction of grazing ruminant animals, directly by increasing production of ROS in the organism, or indirectly, because the quality of fresh or conserved forage can be lowered. Notably, a reduction in forage cobalt content has thus been reported under conditions of heavy sustained rain, leading to vitamin B12 deficiencies.

Large fields of precise knowledge on all those aspects are lacking. However, apart from the necessary veterinarian care, production systems could be adapted to try to anticipate the different sources of vitamin and mineral trace-element deperdition, notably the hazardous conditions of climatic changes, and the induction of reproduction failure due to deficiencies, decreased viability of the newborn or of subsequent growth, so as to promote sustainable agricultural practices.

\section{ACKNOWLEDGEMENTS}

The authors want to acknowledge the thorough work of criticism of the reviewers who thus took a major part in the final field of this review.

\section{REFERENCES}

[1] Aurousseau B, Durand D, Gruffat D. Peroxydations pendant la gestation chez les monogastriques et les ruminants. INRA Prod Anim 2004, 17: 339-354.

[2] Halliwell B, Gutteridge JMC. Free Radical Biology and Medecine, 3rd ed, Oxford, Oxford University Press, 1999.

[3] Pryor WA. Oxy-radicals and related species: their formation, lifetimes, and reactions. Ann Rev Physiol 1986, 48: 657-667.

[4] Aurousseau B. Les radicaux libres dans l'organisme des animaux d'élevage : conséquences sur la reproduction, la physiologie et la qualité de leurs produits. INRA Prod Anim 2002, 15: 67-82.

[5] Bilodeau JF, Hubel CA. Current concepts in the use of antioxidants for the treatment of preeclampsia. J Obstet Gynaecol Can 2003, 25: 742-750.

[6] Neuzil J, Gebicki JM, Stocker R. Radicalinduced chain peroxidation of proteins and its inhibition by chain breaking antioxidants. Biochem J 1993, 293: 601-606.

[7] Porter NA, Caldwell SE, Mills KA. Mechanisms of free radical oxidation of unsaturated lipids. Lipids 1995, 30: 277-290.

[8] Raijmakers MT, Dechend R, Poston L. Oxidative stress and preeclampsia: rationale for antioxidant clinical. Hypertension 2004, 44: 374-380.

[9] Yu BP. Cellular defenses against damage from reactive oxygen species. Physiol Rev 1994, 74: 139-162.

[10] Dean RT, Fu S, Stocker R, Davies MJ. Biochemistry and pathology of radicalmediated protein oxidation. Biochem J 1997, 324: 1-18.

[11] Finkel T. Oxidant signals and oxidative stress. Current Opinion Cell Biol 2003, 15: 247-254.

[12] Haddad JJ. Antioxidant and prooxidant mechanisms in the regulation of redoxsensitive transcription factors. Cell Signal 2002, 14: 879-897.

[13] Colavitti R, Pani G, Bredogni B, Anzevino $\mathrm{R}$, Borello S, Waltenberger J, Galeotti T. Reactive oxygen species as downstream mediators of angiogenic signaling by vascular endothelial growth factor receptor2/KDR. J Biol Chem 2002, 277: 31013108.

[14] Johri RK, Dasgupta PR. Hydrogen peroxide formation in the uterus under hormoneinduced conditions. J Endocrinol 1980, 180: 477-481. 
[15] Kurozumi R, Kojima S. Increase of intracellular glutathione by low-level NO mediated by transcription factor $\mathrm{NF}-\kappa \mathrm{B}$ in RAW264.7 cells. Biochim Biophys Acta 2004, 1744: 58-67.

[16] Meier B, Radeke HH, Selle S, Younes M, Sies H, Resch K, Habermehl GG. Human fibroblast release oxygen species in response to interleukin-1 or tumor necrosis factor- $\alpha$. Biochem J 1989, 263: 539-545.

[17] Leonard SS, Harris GK, Shi X. Metalinduced oxidative stress and signal transduction. Free Radic Biol Med 2004, 37: 1921-1942.

[18] Morel Y, Barouki R. Influence du stress oxydant sur la régulation des gènes. Médecine/Sciences 1998, 14: 713-721.

[19] Bao Y, Jemth P, Mannervik B, Williamson G. Reduction of thymine hydroperoxide by phospholipid hydroperoxide glutathione peroxidase and glutathione transferase. FEBS Lett 1997, 410: 210-212.

[20] Fernando MR, Nanri H, Yoshitake S, Nagata-Kuno K, Minakami S. Thioredoxin regenerates proteins inactivated by oxidative stress in endothelial cells. Eur J Biochem 1992, 209: 917-922.

[21] Tesoriere L, Bongiorno A, Pintaudi AM, D'Anna R, D'Arpa D, Livrea MA. Synergystic interactions between vitamin $\mathrm{A}$ and vitamin $\mathrm{E}$ against lipid peroxidation in phosphatidylcholine liposomes. Arch Biochem Biophys 1996, 326: 57-63.

[22] Caniggia I, Winter JL. Adriana and Luisa Castelluci award lecture 2001. Hypoxia Inducible Factor-1: oxygen regulation of trophoblast differentiation in normal and pre-eclamptic pregnancies - A review. Placenta 2002, 23 (Suppl A): S47-S57.

[23] Duran-Reyes G, Gomez-Melendez MD, La Brena GM, Mercado-Pichardo E, MedinaNavarro RM, Hicks-Gomez JJ. Nitric oxide synthesis inhibition suppresses implantation and decreases cGMP concentration and protein peroxidation. Life Sci 1999, 65: 2259-2268.

[24] Qanungo S, Mukherjea M. Ontogenic profile of some antioxidants and lipid peroxidation in human placental and fetal tissues. Mol Cell Biochem 2000, 215: 11-19.

[25] Fantel AG, Mackler B, Stamps LD, Tran TT, Person RE. Reactive oxygen species and DNA oxidation in fetal rat tissues. Free Radic Biol Med 1998, 25: 95-103.

[26] Burdon RH. Superoxide and hydrogen peroxide in relation to mammalian cell proliferation. Free Radic Biol Med 1995, 18: 775-794.
[27] Miller MJS, Voelker CA, Olester S, Thompson JH, Zhang XJ, Rivera D, ElobyChildress S, Liu X, Clarf DA, Pierce MR. Fetal growth retardation in rats may result from apoptosis: rate of peroxinitrite. Free Radic Biol Med 1996, 21: 619-629.

[28] Ishibashi M, Akazawa S, Sakamaki H, Matsumoto K, Yamasaki H, Yamaguchi Y, Goto S, Urata Y, Kondo T, Nagataki S. Oxygen-induced embryopathy and the significance of glutathione-dependent antioxidant system in the rat embryo during early organogenesis. Free Radic Biol Med 1997, 22: 447-454.

[29] Ashworth CJ, Antipatis C. Micronutrient programming of development throughout gestation. Reproduction 2001, 122: 527 535.

[30] Keen CL, Hanna LA, Lanoue L, UriuAdams JY, Rucker RB, Clegg MS. Developmental consequences of trace mineral deficiencies in rodents: Acute and long-term effects. J Nutr 2003, 133: 1477S-1480S.

[31] Laloraya M, Kumar GP, Laloraya MM. A possible role of superoxide anion radical in the process of blastocyst implantation in Mus musculus. Biochem Biophys Res Commun, 1989, 161: 762-770.

[32] Ishida K, Tsukimori K, Nagata $H$, Koyanagi T, Akazawa K, Nakano H. Is there a critical gestational-age in neutrophil superoxide production activity? Blood 1995, 85: 1331-1333.

[33] Manes C, Lai NC. Nonmitochondrial oxygen utilization by rabbit blastocysts and surface production of superoxide radicals. J Reprod Fertil 1995, 104: 69-75.

[34] Guillomot M, Flechon JE, Leroy E. Développement et implantation du blastocyste. In: Thibaut C, Levasseur MC (Eds), La reproduction chez les mammifères et l'homme, Édition Marketing, Paris, 1991, pp 379-402.

[35] Dixit VD, Parvizi N. Pregnancy stimulates secretion of adrenocorticotropin and nitric oxide from peripheral bovine lymphocytes. Biol Reprod 2001, 64: 242-248.

[36] Massman GA, Zhang J, Figueroa JP. Functional and molecular characterization of nitric oxide synthase in the endometrium and myometrium of pregnant sheep during the last third of gestation. Am J Obstet Gynecol 1999, 181: 116-125.

[37] Allen RG, Keogh BP, Tresini M, Gerhard GS, Volker C, Pignolo RJ, Horton J, Cristofalo VJ. Development and age- 
associated differences in electron transport potential and consequences for oxidant generation. J Biol Chem 1997, 272: 2480524812.

[38] Genbacev O, Zhou Y, Ludlow JW, Fisher SJ. Regulation of human placental development by oxygen tension. Science 1997, 277: 1669-1672.

[39] Kim A, Murphy MP, Oberley TD. Mitochondrial redox state regulates transcription of the nuclear-encoded mitochondrial protein manganese superoxide dismutase: a proposed adaptative response to mitochondrial redox imbalance. Free Radic Biol Med 2005, 38: 644-654.

[40] Rodriguez AM, Carrico PM, Mazurkiewicz JE, Melendez JA. Mitochondrial or cytosolic catalase reverses the MnSOD dependent inhibition of proliferation by enhancing respiratory chain activity, net ATP production, and decreasing the steady state level of $\mathrm{H}_{2} \mathrm{O}_{2}$. Free Radic Biol Med 2000, 29: 801813.

[41] Milczarek R, Klimek J, Zelewski L. The effects of ascorbate and alpha-tocopherol on the NADPH-dependent lipid peroxidation in human placental mitochondria. Mol Cell Biochem 2000, 210: 65-73.

[42] Thibodeau PA, Koksis-Bedard M, Courteau J, Niyonsenga T, Paquette B. Thiols can either enhance or suppress DNA damage induction by catecholoestrogens. Free Radic Biol Med 2001, 30: 62-73.

[43] Kukiela E, Cederbaum AI. NADPH- and $\mathrm{NADH}$-dependent oxygen radical generation by rat liver nuclei in the presence of redox cycling agents and iron. Arch Biochem Biophys 1990, 283: 326-333.

[44] Schreck R, Albermann KIJ, Bauerle PA. Nuclear factor $\mathrm{kB}$ : an oxidative stressresponsive transcription factor of eukaryotic cells (a review). Free Radic Res Commun 1992, 17: 221-237.

[45] Li HL, Byrnes RW. Association of redoxactive iron bound to high molecular weight structures in nuclei with inhibition of cell growth by $\mathrm{H}_{2} \mathrm{O}_{2}$. Free Radic Biol Med 1999, 26: 49-60.

[46] Forsmark-Andree P, Dallner G, Ernster L. Endogenous ubiquinol prevents protein modification accompanying lipid peroxidation in beef heart submitochondrial particles. Free Radic Biol Med 1995, 19: 749757.

[47] Kakuta K, Orino K, Yamamoto S, Watanabe K. High levels of ferritin and its iron in fetal bovine serum. Comp Biochem Physiol 1997, 118A: 165-169.
[48] Keyer K, Imlay JA. Superoxide accelerates DNA damage by elevating free-iron levels. Proc Natl Acad Sci 1996, 93: 1363513640.

[49] Wood ZA, Poole LB, Karplus PA Peroxiredoxin evolution and the regulation of hydrogen peroxide signaling. Science 2003, 300: 650-653.

[50] Goto Y, Noda Y, Narimoto K, Umaoka Y, Mori T. Oxidative stress on mouse embryo development in vitro. Free Radic Biol Med 1992, 13: 47-53.

[51] Wang X, Falcone T, Attaran M, Goldberg JM, Agarwal A, Sharma RK. Vitamin C and vitamin $\mathrm{E}$ supplementation reduce oxidative stress-induced embryo toxicity and improve the blastocyst development rate. Fertil Steril 2002, 78: 1272-1277.

[52] Callapina M, Zhou J, Schmid T, Kohl R, Brune B. NO restores HIF-1 alpha hydroxylation during hypoxia: Role of reactive oxygen species. Free Radic Biol Med 2005, 39: 925-936.

[53] Fischer B, Bavister BD. Oxygen-tension in the oviduct and uterus of rhesus-monkeys, hamsters and rabbits. J Reprod Fertil 1993, 99: 673-679.

[54] Jauniaux E, Watson A, Burton G. Evaluation of respiratory gases and acid-base gradients in human fetal fluids and uteroplacental tissue between 7 and 16 weeks' gestation. Am J Obstet Gynecol 2001, 184: 998-1003.

[55] Jauniaux E, Hempstock J, Greenwold N, Burton GJ. Trophoblastic oxidative stress in relation to temporal and regional differences in maternal placental blood flow in normal and abnormal early pregnancies. Am J Pathol 2003, 162: 115-125.

[56] Houghton FD, Thompson JG, Kennedy CJ, Leese HJ. Oxygen consumption and energy metabolism of the early mouse embryo. Mol Reprod Dev 1996, 44: 476-485.

[57] Kinzey WG. Endocrine function of the placenta in thiamine-deficient rats. Proc Soc Exp Biol Med 1970, 134: 1-4.

[58] Hommes FA, Kraan GPB, Berger R. The regulation of ATP synthesis in the fetal rat liver. Enzyme 1973, 15: 351-360.

[59] Lukienko PI, Mel'nichenko NG, Zverinskii IV, Zabrodskaya SV. Antioxidant properties of thiamine. Bull Exp Biol Med 2000, 130: 874-876.

[60] Barber T, Borras E, Torres L, Garcia C, Cabezuelo F, Lloret A, Pallardo FV, Vina JR. Vitamin A deficiency causes oxidative 
damage to liver mitochondria in rats. Free Radic Biol Med 2000, 29: 1-7.

[61] Tesoriere L, D'Arpa D, Re R, Livrea MA. Antioxidant reactions of all-trans retinol in phospholipid bilayers: effects of oxygen partial pressure, radical fluxes, and retinol concentration. Arch Biochem Biophys 1997, 343: 13-18.

[62] Takahashi YI, Smith JE, Goodman DS Vitamin A and retinol-binding protein metabolism during fetal development in the rat. Am J Physiol 1977, 233: E263-E272.

[63] Antipatis C, Ashworth CJ, Riley SC, Hannah L, Hoggard N, Lea RG. Vitamin A deficiency during rat pregnancy alters placental TNF-alpha signalling and apoptosis. Am J Reprod Immunol 2002, 47: 151-158.

[64] Chan AC, Chow CK, Chiu D. Interaction of antioxidants and their implication in genetic anemia. Proc Soc Exp Biol Med 1999, 222: 274-282.

[65] Levavasseur F, Miyadera H, Sirois J, Tremblay ML, Kita K, Shoubridge E, Hekimi S. Ubiquinone is necessary for mouse embryonic development but is not essential for mitochondrial respiration. J Biol Chem 2001, 276: 46160-46164.

[66] Kelso GF, Porteous CM, Coulter CV, Hughes G, Porteous WK, Ledgerwood EC, Smith RA, Murphy MP. Selective targeting of a redox-active ubiquinone to mitochondria within cells. Antioxidant and antiapoptotic properties. J Biol Chem 2001, 276: 4588-4596.

[67] Beilstein MA, Whanger PD. Effects of vitamin B-6 deficiency on selenium metabolism in the rat. J Nutr 1989, 119: 1962-1972.

[68] Beutler E. Glutathione reductase: stimulation in normal subjects by riboflavine supplementation. Science 1969, 165: 613-618.

[69] Choe E, Min DB. Chemistry and reactions of reactive oxygen species in foods. J Food Sci 2005, 70: R142-R159.

[70] Jain SK, Lim G. Pyridoxine and pyridoxamine inhibits superoxide radicals and prevents lipid peroxidation, protein glycosylation and $\left(\mathrm{Na}^{+} / \mathrm{K}^{+}\right)$-ATPase activity reduction in high glucose-treated human erythrocytes. Free Radic Biol Med 2001, 30: 232-237.

[71] Yant LJ, Ran Q, Rao L, Van Remnen H, Shibatani T, Belter JG, Motta L, Richardson A, Prolla TA. The selenoprotein Gpx4 is essential for mouse development and protects from radiation and oxidative damage insults. Free Radic Biol Med 2003, 34: 496-502.
[72] Nomura K, Imai H, Koumura T, Kobayashi T, Nakagawa Y. Mitochondrial phospholipid hydroperoxide glutathione peroxidase inhibits the release of cytochrom $\mathrm{c}$ from mitochondria by suppressing the peroxidation of cardiolipin in hypoglycemiainduced apoptosis. Biochem J 2000, 351: 183-193.

[73] Maiorino M, Coassin M, Roveri A, Ursini F. Microsomal lipid peroxidation: effect of vitamin $\mathrm{E}$ and its functional interaction with phospholipid hydroperoxide glutathione peroxidase. Lipids 1989, 24: 721726.

[74] Huang TT, Carlson EJ, Kozy HM, Mantha S, Goodman SI, Ursell PC, Epstein CJ. Genetic modification of prenatal lethality and dilated cardiomyopathy in Mn superoxide dismutase mutant mice. Free Radic Biol Med 2001, 31: 1101-1110.

[75] Hoffman LH, Davenport GR, Brash AR Endometrial prostaglandins and phospholipase activity related to implantation in rabbits: effects of dexamethasone. Biol Reprod 1984, 30: 544-555.

[76] Quirk MF, Norton BW. The relationship between the cobalt nutrition of ewes and the vitamin B12 status of ewes and the lamb. Aust J Agric Res 1987, 38: 1071-1082.

[77] Pfarrer C, Hirsch P, Guillomot M, Leiser $\mathrm{R}$. Interaction of integrin receptors with extracellular matrix is involved in trophoblast giant cell migration in the bovine placentomes. Placenta 2003, 24: 588-597.

[78] Liu R, Buettner GR, Oberley LW. Oxygen free radicals mediate the induction of manganese superoxide dismutase gene expression by TNF- $\alpha$. Free Radic Biol Med 2000, 28: 1197-1205.

[79] Arrigo AP. Gene expression and the thiol redox state. Free Radic Biol Med, 1999, 27 936-944.

[80] Allen RG, Balin AK. Oxidative influence on development and differentiation: an overview of a free radical theory of development. Free Radic Biol Med 1989, 6: 631-661.

[81] Agani FH, Pichiule P, Chavez JC, Lamanna JC. The role of mitochondria in the regulation of hypoxia-inducible factor-1 expression during hypoxia. J Biol Chem 2000, 275: 35863-35867.

[82] Chandel NS, McClintock DS, Feliciana CE, Wood TM, Melandy JA, Rodriguez AM, Schinacker PT. Reactive oxygen species generated at mitochondria complex III stabilize hypoxia-inducible factor- $1 \alpha$ during 
hypoxia. J Biol Chem 2000, 275: 2513025138.

[83] Xavier F, Lagarrigue S, Guillomot M, GaillardSanchez I. Expression of c-fos and jun protooncogenes in ovine trophoblasts in relation to interferon-tau expression and early implantation process. Mol Reprod Dev 1997, 46: 127-137.

[84] Guillomot M. Cellular interactions during implantation in domestic ruminants. J Reprod Fertil 1995, 49 (Suppl): 39-51.

[85] Sasazuki T, Okazaki T, Tada K, SakonKomazawa S, Katano M, Tanaka M, Yagita H, Okumura K, Tominaga N, Hayashizaki Y, Okazaki Y, Nakano H. Genome wide analysis of TNF-inducible genes reveals that antioxidant enzymes are induced by TNF and responsible for elimination of ROS. Mol Immunol 2004, 41: 547-551.

[86] Maden M. Vitamin A in embryonic development. Nutr Rev 1994, 2: S3-S12.

[87] Isoherranen K, Peltola V, Laurikainen L, Punnonen J, Laihia J, Ahotupa M, Punnonen K. Regulation of copper/zinc and manganese superoxide dismutase by UVB irradiation, oxidative stress and cytokines. J Photochem Photobiol B Biol 1997, 40: 288-293.

[88] Munim A, Asayama K, Dobaschi K, Suzuki K, Kawaoia A, Kato K. Immunohistochemical localization of superoxide dismutase in fetal and neonatal rat-tissues. J Histochem Cytochem 1992, 40: $1705-1713$

[89] Lee HC, Wei YH. Mitochondrial biogenesis and mitochondrial DNA maintenance of mammalian cells under oxidative stress. Int J Biochem Cell Biol 2005, 37: 822-834.

[90] Mackler B, Grace R, Duncan HM. Stades of mitochondrial development during embryogenesis in the rat. Arch Biochem Biophys 1971, 144: 603-610.

[91] Sandau KB, Fandrey J, Brune B. Accumulation of HIF-1 alpha under the influence of nitric oxide. Blood 2001, 97: 1009-1015.

[92] Bianchi A, Becuwe P, Franck P, Dauca M. Induction of MnSOD gene by arachidonic acid is mediated by reactive oxygen species and p39 MAPK signaling pathway in human HepG2 hepatoma cells. Free Radic Biol Med 2002, 32: 1132-1142.

[93] Boggess KA, Oury TD, Kay HH, Crapo JD. Extracellular superoxide dismutase localization and activity within the human placenta. Placenta 1998, 19: 417-422.
[94] Huang RFS, Hsu YC, Lin HL, Yang FL. Folate depletion and elevated plasma homocysteine promote oxidative stress in rat livers. J Nutr 2002, 131: 33-38.

[95] Jankowski MA, Uriu-Hare JY, Rucker RB, Rogers JM, Keen CL. Maternal zinc deficiency, but not copper deficiency or diabetes, results in increased embryonic cell death in the rat: implications for mechanisms underlying normal development. Teratology 1995, 31: 85-93.

[96] Keen CL, Uriu-Hare JY, Hawk SN, Jankowski MA, Daston GP, Kwik-Uribe CL, Rucker BB. Effect of copper deficiency on perinatal development and pregnancy outcome. Am J Clin Nutr 1998, 67: 1003S$1011 \mathrm{~S}$

[97] Wegger I, Palladin B. Vitamin C deficiency causes hematological and skeletal abnormalities during fetal development in swine. J Nutr 1994, 124: 241-248.

[98] Chappel LC, Seed PT, Briley AL, Kelly FJ, Lee R, Hunt BJ, Parmar K, Bewley SJ, Shennan AH, Steer PJ, Poston L. Effect of antioxidants on the occurrence of preeclampsia in women at increased risk: a randomized trial. Lancet 1999, 354: 810 816.

[99] Wacker J, Fruhauf J, Schulz M, Chiwora FM, Volz J, Becker K. Riboflavin deficiency and preeclampsia. Obstet Gynecol 2000, 96: 38:44.

[100] Scholl TO, Johnson WG. Folic acid: influence on the outcome of pregnancy. Am J Clin Nutr 2000, 71: 1295S-1303S.

[101] Tremblay GF, Matte JJ, Dufour JJ, Brisson GJ. Survival rate and development of fetuses during the first 30 days of gestation after folic acid addition to a swine diet. J Anim Sci 1989, 67: 724-732.

[102] Duncan WRH, Morrison ER, Garton GA Effects of cobalt deficiency in pregnant and post-parturient ewes and their lambs. $\mathrm{Br} \mathrm{J}$ Nutr 1981, 46: 337-344.

[103] Powers HJ, Riboflavin (vitamin B-2) and health. Am J Clin Nutr 2003, 77: 13521360 .

[104] Grzelak A, Rychlik B, Baptosz G. Lightdependent generation of reactive oxygen species in cell culture media. Free Radic Biol Med 2001, 30: 1418-1425.

[105] Gajkowska B, Walski M, Olszewska H. Characterization of thiamine pyrophosphatase positive phagocytic cells in the neural lobe of rat pituitary. Folia Neuropathologica 1998, 36: 109-116. 
[106] Benderitter M, Hadj-Saad F, Lhuissier M, Maupoil V, Guilland JC, Rochette L. Effects of exhaustive exercise and vitamin B6 deficiency on free radical oxidative process in male trained rats. Free Radic Biol Med 1996, 21: 541-549.

[107] Grimble RF. Modification of inflammatory aspects of immune function by nutrients. Nutr Res 1998, 18: 1297-1317.

[108] Kennedy D.G., Young P.B., Blanchflower W.J., Scott J.M., Weir D.G., Molloy A.M., Kennedy S. Cobalt-vitamin B12 deficiency causes lipid accumulation lipid peroxydation and decreased alpha-tocopherol concentrations in the liver of sheep. Int J Vitam Nutr Res 1994, 64: 270-276.

[109] Joshi R, Adhikari S, Patro BS, Chattopadhyay S, Mukherjee T. Free radical scavenging behaviour of folic acid: evidence for possible antioxidant activity. Free Radic Biol Med 2001, 30: 1390-1399.

[110] Lucock M, Yates Z, Glanville T, Leeming R, Simpson N, Daskalakis I. A critical role for B-vitamin nutrition in human developmental and evolutionary biology. Nutr Res 2003, 23: 1463-1475.

[111] Marsh EN. Coenzyme B12(cobalamin)dependent enzymes. Essays Biochem 1999, 34: 139-154.

[112] Wagner C. Biochemical role of folate in cellular metabolism. In: Bailey LB (Ed), Folate in Health and Disease, Marcel Dekker, 1995, pp 23-42.

[113] Ulvund MJ, Pestalozzi M. Ovine whiteliver disease (OWLD). Botanical and chemical composition of pasture grass. Acta Vet Scand 1990, 31: 257-265.

[114] Clark RG, Wright DF, Millar KR, Rowland JD. Reference curves to diagnose cobalt deficiency in sheep using liver and serum vitamin B12 levels. NZ J Agric Res 1989, 37: 7-11.

[115] Sharma VS, Pilz RB, Boss GR, Magde D. Reactions of nitric oxide with vitamin B12 and its precursor, cobinamide. Biochemistry 2003, 42: 8900-8908.

[116] Danishpajooh IO, Gudi T, Chen YC, Kharitonov VG, Sharma VS, Boss GR. Nitric oxide inhibits methionine synthase activity in vivo and disrupts carbon flow through the folate pathway. J Biol Chem 2001, 276: 27296-27303.

[117] Smith KL, Harrison JH, Hancock DD, Todhunter DA, Conrad HR. Effect of vitamin $\mathrm{E}$ and selenium supplementation on incidence of clinical mastitis and duration of clinical symptoms. J Dairy Sci 1984, 67: 1293-1300.
[118] Fischer GE. Effect of cobalt deficiency in the pregnant ewe on reproductive performance and lamb viability. Res Vet Sci 1991, 50: 319-327.

[119] Kott RW, Thomas VM, Hatfield PG, Evans T, Davis KC. Effects of dietary vitamin E supplementation during late pregnancy on lamb mortality and ewe productivity. J Am Vet Med Assoc 1998, 212: 997-1000.

[120] Yeoman GH. Copper in relation to lamb losses. Vet Rec 1983, 113: 547.

[121] Weiss WP, Todhunter DA, Hogan JS, Smith KL. Effect of duration of supplementation of selenium and vitamin $\mathrm{E}$ on periparturient dairy cows. J Dairy Sci 1990, 73: 31873194.

[122] Saez T, Ramos JJ, Marca MC, Sanz MC, Fernandez A, Verde MT. Studies on selenium in sheep: effect of various form of supplementation on the production of flocks. World Rev Anim Prod 1994, 29: 22 27.

[123] Stangl GI, Schwarz FJ, Muller H, Kirchgessner M. Evaluation of the cobalt requirement of beef cattle based on vitamin B12, folate, homocysteine and methylmalonic acid. Brit J Nutr 2000, 84: 645-653.

[124] Girard CL, Matte JJ, Levesque J. Responses of serum folates of preruminant and ruminant calves to a dietary supplement of folic acid. J Anim Sci 1992, 70, 2847-2851.

[125] Girard CL, Matte JJ, Roy GL. Serum folates in young heifers. Brit J Nutr 1989, 61: 595-600.

[126] Dumoulin PG, Girard CL, Matte JJ, StLaurent GJ. Effects of a parenteral supplement of folic acid and its interaction with level of feed intake on hepatic tissues and growth performance of young dairy heifers. J Anim Sci 1991, 69: 1657-1666.

[127] Girard CL, Matte JJ, Tremblay JF. Gestation and lactation of dairy cows: a role for folic acid? J Dairy Sci 1995, 78: 404-411.

[128] Kimber RJ, Allen SH. An abnormality of the bone marrow associated with vitamin $\mathrm{E}$ deficiency in sheep. Brit J Nutr 1975, 33: 357-371.

[129] Dan Dusseldorp M, Schneede J, Refsun H, Upeland PM, Thomas CMG, de Boer E, van Staveren WA. Risk of persistent cobalamin deficiency in adolescents fed a macrobiotic diet in early life. Am J Clin Nutr 1999, 69: 664-671. 